\title{
Leptin Reduces Body Weight Gain in Neonatal Rats
}

\author{
CHUN-SU YUAN, ANOJA S. ATTELE, LIU ZHANG, JAMES P. LYNCH, JING-TIAN XIE, \\ AND ZHI Q. SHI
}

Committee on Clinical Pharmacology [C.-S.Y.] and Department of Anesthesia and Critical Care [A.S.A., L.Z., J.P.L., J.-T.X.], The Pritzker School of Medicine, The University of Chicago, Chicago, Illinois 60637, U.S.A.; and Department of Pharmacology, Amgen, Thousand Oaks, California 91320, U.S.A. [Z.Q.S.]

\begin{abstract}
Leptin (OB protein) elicits a neuroendocrine response to starvation and states of nutritional abundance to stabilize the proportion of body fat. Leptin has dramatic effects on food intake and energy expenditure in adult and juvenile rodents. However, whether the neonatal period is associated with the development of an effective leptin feedback system is still not known. In this study, we evaluated the effects of peripherally administered leptin on body weight changes in neonatal rats during the early suckling period (from birth to $10 \mathrm{~d}$ ). Our results show that daily i.p. injections of leptin $(0.3 \mu \mathrm{g} / \mathrm{g}$ and $1.0 \mu \mathrm{g} / \mathrm{g})$ to neonatal rats led to a significant reduction in weight gain over $10 \mathrm{~d}$ compared
\end{abstract}

\section{ABSTRACT}

with the control group ( $p<0.01$ and $p<0.01$, respectively). Concomitant with a reduction in weight gain, retroperitoneal fat pad weight also significantly decreased in the leptin-treated group. Our data indicate that the potential for energy balance regulation by leptin occurs in the first day after birth. In addition, we also observed that $3 \mathrm{~d}$ after discontinuing leptin treatment, the body weight as well as the fat pad weight of leptin-treated pups returned to the control level. Our results demonstrate that leptin reduces body weight gain in neonatal rats. (Pediatr Res 48: 380-383, 2000)
Leptin, the secreted product of the obese $(o b)$ gene, regulates food intake and energy expenditure $(1,2)$. Leptin may increase energy expenditure by enhancing systemic (3) and brown adipose tissue glucose utilization (4). Thus far, adipose tissue (5) as well as the stomach (6) have been identified as sites of leptin synthesis. Leptin acts as a link in the feedback loop between adipose tissue and satiety centers in the hypothalamus, resulting in a decrease in appetite and an increase in energy expenditure $(5,6)$. However, it is also possible that sources of leptin other than adipose tissue play a similar role. For example, the epithelium of the gastric fundus and gastric glands not only synthesize and store leptin, but also secrete leptin in response to food intake (7). Arterially injected leptin increases gastric vagal nerve activity (8), and these afferent inputs link nutrient-related events in the gastrointestinal tract to the CNS areas that mediate the control of food intake $(9,10)$. We recently observed that leptin applied to the gastric mucosa increases neuronal activity in the nucleus tractus solitarius of the brain stem, the first relay station of autonomic afferent inputs (11).

Received December 30, 1999; accepted April 4, 2000.

Correspondence: Dr. Chun-Su Yuan, Department of Anesthesia and Critical Care, The University of Chicago Medical Center, 5841 S. Maryland Avenue, MC 4028, Chicago, IL 60637, U.S.A.

This work is supported in part by the Brain Research Foundation, the Tang Family Foundation, and Clinical Practice Enhancement and Anesthesia Research Foundation.
There is evidence that leptin regulates body weight during the postnatal period $(12,13)$. However, in young rodents, unlike in adults, leptin decreases body weight gain via increasing energy expenditure by varying the metabolic rate (13). In suckling pups (from birth to $21 \mathrm{~d}$ ), because food intake is restricted by the maternal milk supply, the energy expended for thermoregulation limits the energy left for growth and fat deposition (14). Moreover, endogenous leptin levels of postnatal rats correspond to changes in dietary fat intake. Trottier et al. (15) reported that suckling rat pups fed higher levels of fat in milk have elevated circulating leptin levels. A pharmacological dose of leptin was reported to cause a significant reduction in juvenile fat deposition (13).

Although several studies have reported on body weight regulation by leptin in juvenile animals $(12,13)$, there are few reports on leptin's effects in neonates. It has been postulated that during the early suckling period (from birth to $10 \mathrm{~d}$ ) leptin may not regulate fat deposition (15). However, there is a significant positive correlation between body weight gain in neonates and rise in leptin levels (16). To date, no in vivo study has been done on leptin's pharmacological effects in animals immediately after birth, in which adipose tissue and the appetite regulatory system are immature. The objective of this study was to evaluate the effects of peripherally injected leptin on body weight changes in neonatal rats during the early suckling period. 


\section{MATERIALS AND METHODS}

Experimental protocol. The study protocol was approved by the Institutional Animal Care and Use Committee of the University of Chicago. Timed pregnant Sprague-Dawley rats were obtained from Harlan Sprague-Dawley (Madison, WI, U.S.A.). Nine litters (63 pups) of both sexes were used. Litters were individually housed and were allowed access to food and water ad libitum. Pups were reared by their biologic mother.

Pups of each litter were randomly assigned into three groups: control (PBS vehicle) group, low-dose leptin (0.3 $\mu \mathrm{g} / \mathrm{g})$ group, and high-dose leptin $(1.0 \mu \mathrm{g} / \mathrm{g})$ group. Daily i.p. injections of test drug or vehicle was given to pups for $9 \mathrm{~d}$, and all pups were weighed daily. After d 9, i.p. injections were discontinued, and all pups were weighed again on d 10 and d 12. Fine needles ( 28 gauge) were used for all i.p. injections to minimize pain and discomfort. After each injection, rats were immediately returned to the mother to reduce distress.

To confirm the accuracy of injections, in another five pups, a colored solution ( $1 \%$ pontamine sky blue) was injected i.p. Five minutes after i.p. injections, the animals were euthanized using $100 \% \mathrm{CO}_{2}$. Dissection results showed that the colored solution was localized in the peritoneal cavity. Moreover, there were no signs of internal organ penetration.

Another 24 pups were used for the measurement of fat pad weight. Twelve pups received daily leptin $(1.0 \mu \mathrm{g} / \mathrm{g})$ injections for $9 \mathrm{~d}$ and the remaining 12 pups received daily PBS vehicle injections for the same period of time. On d 10, six animals of each group were euthanized, and right retroperitoneal fat pads were removed and weighed. On d 12, the remaining 12 animals (six animals of each group) were euthanized, and the right fat pads were removed and weighed.

Drug. The methionyl murine leptin was provided by Amgen, Inc. (Thousand Oaks, CA, U.S.A.). Leptin was purified by ion exchange and hydrophobic interaction chromatography to have a purity of $>99 \%$ using HPLC and a Coomassie assay (Amgen).

Data and statistical analysis. The animal body weight data with or without leptin administrations were analyzed using ANOVA for repeated measures. For body weight changes between $\mathrm{d} 10$ and d 12, as well as for fat pad weight changes with or without leptin injection, $t$ test was used. In all cases, $p<0.05$ was considered statistically significant.

\section{RESULTS}

Table 1 shows that leptin reduces body weight gain in neonatal rats. The body weight of each neonatal rat on $\mathrm{d} 1$ was normalized to $100 \%$, and the body weight changes after leptin treatment from d 1 to 12 were compared with the control data. Compared with the control group $(n=11)$, the weight gain of pups, from d 1 to 10, who received a single daily i.p. leptin injection of $0.3 \mu \mathrm{g} / \mathrm{g}(n=11)$ or $1.0 \mu \mathrm{g} / \mathrm{g}$ leptin $(n=12)$ for 9 consecutive days was significantly reduced $(p<0.01$ and $p<0.01$, respectively).

For better illustration, in Figure 1, the daily mean weight of pups in control group was adjusted to $100 \%$. The daily percentage in weight change of the two leptin-treated groups was expressed as percentage changes compared with the control group. The dose-related effects of leptin can be seen. The maximum difference in weight-change of pups after $1.0 \mu \mathrm{g} / \mathrm{g}$ leptin treatment was approximately $17 \%$. For both leptin groups, the maximum difference in weight change occurred on d 10 .

As shown in Figure 1, on d 12, i.e. $72 \mathrm{~h}$ after discontinuing leptin treatment, the body weight of the two leptin-treated groups almost returned to control level.

As shown in Figure 2, on d 10, the weights of right retroperitoneal fat pads from control group $(n=6)$ and leptin group $(n=6)$ were $283 \pm 32.7 \mathrm{mg}$ (mean $\pm \mathrm{SD})$ and $132 \pm 30.5 \mathrm{mg}$, respectively. Compared with the control group, the weights of the fat pads in the leptin group was significantly reduced $(p<$ 0.01 ). On $\mathrm{d} 12$, the weights of the fat pads from control group $(n=6)$ and leptin group $(n=6)$ were $334 \pm 39.1 \mathrm{mg}$ and $314 \pm 50.0 \mathrm{mg}$, respectively. Compared with the control group, the weight of the fat pads in the leptin group was not significantly different.

Table 1. Daily effects of leptin administration in reducing body weight gain in neonatal rats

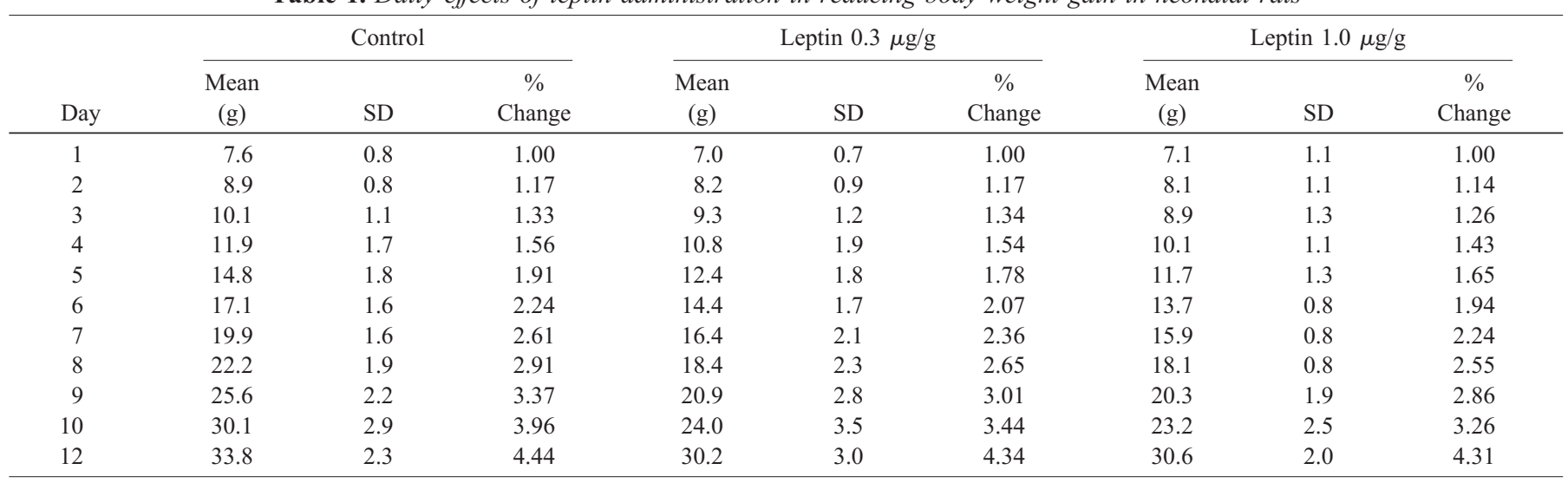

Compared with the control group $(n=11)$, the weight gains of pups who received nine consecutive daily i.p. leptin injections of $0.3 \mu \mathrm{g} / \mathrm{g}(n=11)$ and 1.0 $\mu \mathrm{g} / \mathrm{g}(n=12)$ were significantly reduced ( $p<0.01$ and $p<0.01$, respectively). Leptin treatment was discontinued after $\mathrm{d} 9$, and the body weight of the two leptin-treated groups quickly returned toward control level (on d 12). For percent change, body weight of each animal on d 1 was normalized to $100 \%$, and the weight changes from $\mathrm{d} 2$ to $\mathrm{d} 12$ were compared with $\mathrm{d} 1(100 \%)$. 


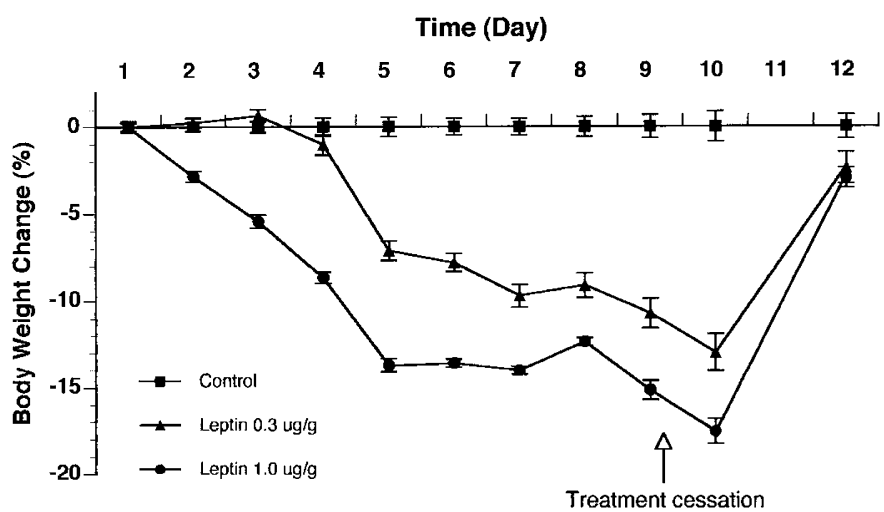

Figure 1. Leptin reduces body weight gain in neonatal rats. The daily mean body weight (from d 1 to 12$)$ of pups in control group $(n=11)$ was adjusted to $100 \%$. The daily percentage weight changes of the two leptin-treated groups, i.e. i.p. administration of leptin $0.3 \mu \mathrm{g} / \mathrm{g}(n=11)$ and $1.0 \mu \mathrm{g} / \mathrm{g}(n=12)$, were expressed as percentage changes compared with the control group. Leptin treatment was discontinued after $\mathrm{d} 9$.

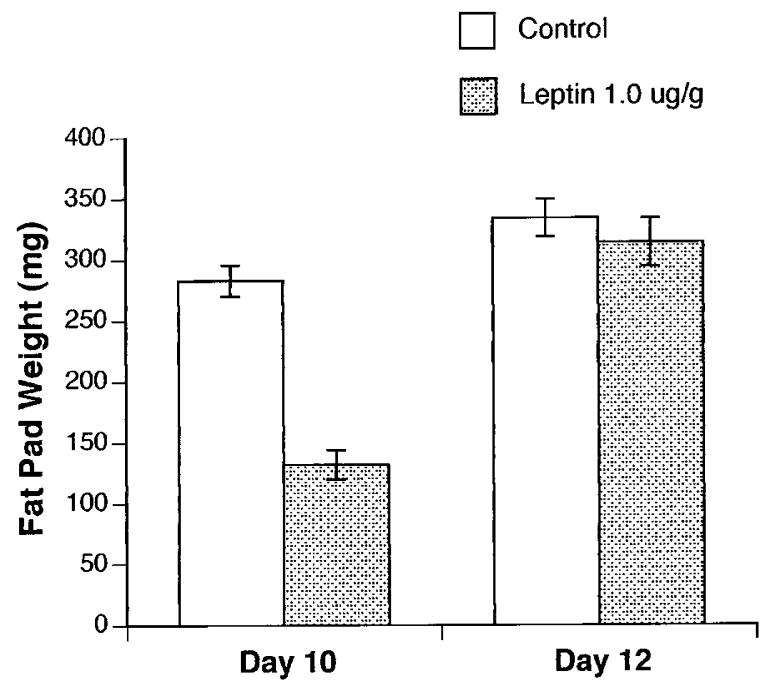

Figure 2. Leptin reduces fat pad weight gain in neonatal rats. On d 10, compared with the control group $(n=6)$, the weight of right retroperitoneal fat pads in leptin group $(n=6)$ reduced significantly. On $\mathrm{d} 12$, compared with the control group $(n=6)$, the weight of the fat pads in the leptin group $(n=6)$ was not significantly different. Daily i.p. leptin $1.0 \mu \mathrm{g} / \mathrm{g}$ administration was discontinued after $\mathrm{d} 9$.

\section{DISCUSSION}

This is the first study to report that peripheral leptin administration from the first day after birth induced a cumulative effect over time to reduce body weight gain in neonates. Previous investigations with adult rodents have shown that leptin causes weight loss by decreasing food intake as well as by increasing energy expenditure $(1,2)$. The animals that were used for the present study were in the early suckling stage, during which milk intake is mainly regulated by the amount of milk the pups can consume (17). It has been reported that in suckling juvenile rats (7-16 d after birth) treated with leptin, the weight-reducing effects of leptin were due solely to increased energy expenditure (13). In rodents, leptin has been reported to increase systemic (3) and brown adipose tissue (4) glucose utilization. The efferent pathways for leptin's effects on energy expenditure may be associated with the activity of the sympathetic nervous system and the subsequent stimulation of heat production in brown adipose tissue (18). Since brown fat is well developed in newborn rodents, it is plausible that leptin caused a significant reduction in weight gain by similar mechanisms in pups used in the present study. It is possible that a reduction in milk intake also contributed to the weight loss. However, it is difficult to artificially feed newborn rats in our study. The youngest rats used in previous studies for milk intake measurement were suckling rats older than $1 \mathrm{wk}(13)$.

In humans (19) and rodents (20), serum leptin can be detected at birth and then it undergoes a rapid decline. These changes may reflect alterations in hormonal and nutritional status (19) during the early neonatal period. Leptin levels in rodents also showed a response to milk intake (20). Our results show that 1- to 10-d-old rat pups are able to adjust fat storage when the signal provided by leptin in the physiologic state is altered by exogenously supplied leptin. The weight-reducing effect of leptin is not likely to be the result of conditioned taste aversion. When leptin was injected into the lateral brain ventricle at a dose that reduced short-term food intake, there were no aversive side effects to saccharine (21).

Although the signaling-competent obese protein receptor $b$ has been found in sites other than adipose tissue, notably the gastric epithelium and gastric glands that also secrete and store leptin (6), leptin is still viewed as an adipose tissue signal to hypothalamic networks involved in feeding. In this study, daily leptin was administered i.p. for 10 consecutive days to evaluate body weight changes in neonatal rats. The highest daily dose of the peptide was $1.0 \mu \mathrm{g} / \mathrm{g}(1.0 \mathrm{mg} / \mathrm{kg})$, which is less than one-tenth of the dose given s.c. to lean juvenile rats (13). It has been shown that the pharmacokinetics of i.p. drug administration is different from the i.v. route. In rats, compared with i.v. injections, a relatively high and sustained drug level can be obtained in the abdominal cavity with low systemic exposure with an i.p. injection (22). The ability of a drug to be retained for longer periods in the peritoneal cavity is directly proportional to its molecular weight (23). With a molecular weight of 16,178 (24), leptin is a qualified candidate. This potentially high and sustained leptin level raises the possibility that the compound may also signal central neural networks from an intra-abdominal organ like the gut. The gastric epithelium and glands have the capability to synthesize and store leptin, and also secrete leptin in response to food intake (6). It has also been reported that leptin injected into the gastric artery increased the spike count of gastric vagal afferents (8). In our recent in vitro neonatal rat study, we observed that leptin applied to the gastric mucosa modulates gastric vagal afferent activity in the nucleus tractus solitarius (11), which has neural connections with the dorsomedial hypothalamic nucleus (2527), an area involved in leptin-mediated weight-reducing effects. In addition to leptin's systemic effect, it is likely that i.p. leptin administration is able to stimulate gastric vagal afferents, and thus establish a direct relationship between peripheral leptin receptors and the CNS. Our results from this study, which show that peripherally injected leptin regulates body weight during the early development stage, support our previous observation that leptin signals the CNS via gastric vagal afferents in neonatal rats (11). 
Plasma leptin levels in infants highly correlate to the size of adipose tissue mass (28). Although fat pad to body weight ratios during the early developmental period are extremely small (15), in this study, the retroperitoneal fat pad weight in leptin-treated pups was found to be significantly reduced. Wang et al. (4) reported that peripherally administered leptin may decrease adiposity by increasing glucose and oxygen utilization in brown adipose tissue while decreasing energy storage in white adipose tissue. The weight decrease in fat pads that we observed supports the notion that leptin increases energy expenditure, and suggests that the effect of leptin on suppression of weight gain can at least partly be attributed to the reduction in adipose tissue mass.

The body weight changes induced by leptin over $10 \mathrm{~d}$ were not uniform. This may reflect changes in leptin receptor expression and/or abdominal organ bindings during the development of the neonatal rat, as well as changes in the hormonal and nutritional status. Interestingly, in this study, we observed that on $\mathrm{d} 10,24 \mathrm{~h}$ after the last i.p. leptin injection, suppression of weight gain continued. However, on d 12, $72 \mathrm{~h}$ after the last i.p. leptin injection, the body weight in leptin-treated groups rapidly returned to the control level. Although i.p. administration was given to achieve a relatively high and sustained drug level, the short half-life $(5-9 \mathrm{~min})$ of leptin $(29,30)$ may partly explain our observation. Our results may provide information for treatment regimen design when leptin is used to control the body weight in different species.

In summary, our data demonstrated that treatment of 1-d-old rat pups with a single daily i.p. injection of murine leptin for $9 \mathrm{~d}$ significantly suppressed weight gain compared with control littermates. The effects of leptin seem to be reversible upon withdrawal of leptin. Our results indicate that the potential for energy balance regulation by leptin occurs within the first several days after birth and suggest that leptin may play a role in regulating the body weight in neonates.

Acknowledgments. The authors thank Tasha K. Lowell and Ji An Wu for their technical assistance.

\section{REFERENCES}

1. Halaas JL, Gajiwala KS, Maffei M, Cohen HL, Chait BT, Rabinowitz D, Lallone RL, Burley SK, Friedman JM 1995 Weight-reducing effects of the plasma protein encoded by the obese gene. Science 269:543-546

2. Pelleymounter MA, Cullen MJ, Baker MB, Hetch R, Winters D, Boone T, Collins F 1995 Effects of the obese gene product on body weight. Science 269:540-543

3. Shi ZQ, Nelson A, Whitcomb L, Wang J, Cohen AM 1998 Intracerebroventricular administration of leptin markedly enhances insulin sensitivity and systemic glucose utilization in conscious rats. Metabolism 47:1274-1280
4. Wang J-L, Chinookoswong N, Scully S, Qi M, Shi Z-Q 1999 Differential effects of leptin in regulation of tissue glucose utilization in vivo. Endocrinology 140:21172124

5. Zhang Y, Proenca R, Maffei M, Barone M, Leopold L, Friedman JM 1994 Positional cloning of the mouse obese gene and its human homologue. Nature 372:425-432

6. Campfield LA, Smith F, Guisez Y, Devos R, Burn P 1995 Recombinant mouse OB protein: evidence for a peripheral signal linking adiposity and central neural networks. Science 269:546-549

7. Bado A, Levasseur S, Attoub S, Kermorgant S, Laigneau J, Bortoluzzi M, Moizi L, Lehy T, Guerre-Millos M, Le Marchand-Brustel Y, Lewin MJM 1998 The stomach is a source of leptin. Nature 394:790-793

8. Wang YH, Tache Y, Sheibel AB, Go VLW, Wei JY 1997 Two types of leptinresponsive gastric vagal afferent terminals: an in vitro single-unit study in rats. Am J Physiol 273:R833-R837

9. Altschuler SM, Bao X, Bieger D, Hopkins DA, Miselis RR 1989 Viscerotopic representation of the upper alimentary tract in the rat: sensory ganglia and nuclei of the solitary and spinal trigeminal tracts. J Comp Neurol 283:248-268

10. Berthoud HR, Jedrzejewska A, Powley TL 1990 Simultaneous labeling of vagal innervation of the gut and afferent projections from the visceral forebrain with dil injected into the dorsal vagal complex. J Comp Neurol 301:65-79

11. Yuan CS, Attele AS, Zhang L, Wu JA, Shi ZQ 1999 Peripheral gastric leptin modulates brain stem neuronal activity in neonates. Am J Physiol 277:G626-G630

12. Rayner DV, Galgliesh GD, Duncan JS, Hardie LJ, Hoggard N, Trayhurn P 1997 Postnatal development of the ob gene system: elevated leptin levels in suckling fa/fa rats. Am J Physiol 42:R446-R450

13. Stehling O, Doring H, Ertl J, Preibisch G, Schmidt I 1996 Leptin reduces juvenile fat stores by altering the circadian cycle of energy expenditure. Am J Physiol 40:R1770 R1774

14. Schmidt I, Kaul R, Heldmaier G 1987 Thermoregulation and diurnal rhythms in 1-week-old rat pups. Can J Physiol Pharmacol 65:1355-1363

15. Trottier G, Koski KG, Brun T, Toufexis DJ, Richard D, Walker C-D 1998 Increased fat intake during lactation modifies hypothalamic-pituitary-adrenal responsiveness in developing rat pups: a possible role for leptin. Endocrinology 139:3704-3711

16. Harigaya A, Kazumichi O, Nako Y, Nagashima K, Morikawa A 1999 Role of serum leptin in the regulation of weight gain in early infancy. Biol Neonate 75:234-238

17. Cramer CP, Blass EM 1983 Mechanisms of control of milk intake in suckling rats. Am J Physiol 245:R154-R159

18. Himms-Hagen J, Ricquier D 1997 Brown adipose tissue. In: Bray G, Bouchard C, James WPT (eds) Handbook of Obesity. Marcel Dekker, New York, pp 415-432

19. Matsuda J, Ichiro Y, Iida M, Murakam T, Yamada M, Sado T, Naito E, Ito M, Shima K, Kuroda Y 1999 Dynamic changes in serum leptin concentrations during the fetal and neonatal periods. Pediatr Res 45:71-75

20. Dessolin S, Schalling M, Champigny O, Lonnqvist F, Ailhaud G, Dani C, Ricquier D 1997 Leptin gene is expressed in rat brown adipose tissue at birth. FASEB J 11:382-387

21. Thiele TE, Van Dijk G, Campfield LA, Smith FJ, Burn P, Woods SC, Bernstein IL, Seeley RJ 1997 Central infusion of GLP-1, but not leptin, produces conditioned taste aversions in rats. Am J Physiol 272:R726-R730

22. Pestieau SR, Stuart OA, Chang D, Jacquet P, Sugarbaker PH 1998 Pharmacokinetics of intraperitoneal gemcitabine in a rat model. Tumori 84:706-711

23. Derrick RL, Meyers CE, Bungay PM, DeVita VT 1978 Pharmacokinetic rationale for peritoneal drug administration in the treatment of ovarian cancer. Cancer Treat Rep $62 \cdot 1-9$

24. Cohen SL, Halaas JL, Friedman JF, Chalt BT, Bennet L, Chang D, Hecht R, Collins F 1996 Human leptin characterization. Nature 382:589

25. Bernardis LL, Bellinger LL 1998 The dorsomedial hypothalamic nucleus revisited: 1998 update. Proc Soc Exp Biol Med 218:284-306

26. Yuan CS, Barber WD 1992 Hypothalamic unitary response to gastric vagal input from the proximal stomach. Am J Physiol 262:G74-G80

27. Yuan CS, Barber WD 1996 Interactions of gastric vagal and peripheral nerves on single neurons of lateral hypothalamus in the cat. Am J Physiol 271:G858-G865

28. Marchini GG, Fried G, Ostlund E, Hagenas L 1998 Plasma leptin in infants: relations to birth weight and weight loss. Pediatrics 101:429-432

29. Vila R, Rafecas I, Fernandez-Lopez JA, Remsar X, Alemany M 1998 Plasma leptin turnover rates in lean and obese Zucker rats. Endocrinology 139:4466-4469

30. Zeng Z, Patterson BW, Klein S, Martin DR, Dagogo-Jack S, Kohrt WM, Miller SB, Landt M 1997 Whole body leptin kinetics and renal metabolism in vivo. Am J Physiol 273:E1102-E1106 